\title{
A RADIOLOGIA ODONTOLÓGICA E O MEIO AMBIENTE
}

\section{THE DENTAL RADIOLOGY AND THE ENVIRONMENT}

\author{
Molina $\mathrm{AB}^{*}$ \\ Bueno $\mathrm{CS}^{*}$ \\ Aida $\mathrm{CA}^{*}$ \\ Castanheira GM* \\ Hada RA* \\ Ishikiriyama $\mathrm{YT}^{*}$ \\ Ono E** \\ Brassaroto GC***
}

\section{RESUMO}

O descarte irregular de resíduos de saúde, especialmente o odontológico, está se tornando um um grande motivo de preocupação. O lixo proveniente de rejeitos no processo radiográfico não é diferente, uma vez que, além de resíduo contaminado, há rejeitos químicos, metais pesados e plásticos. Sendo eles: invólucro do filme radiográfico, soluções processadoras, lâminas de chumbo, películas dos filmes radiográficos - todos eles capazes de causar grande impacto no meio ambiente, se descartados de forma incorreta. Por esse motivo, é imprescindível conscientizar os cirurgiões-dentistas do impacto prejudicial no meio ambiente e, consequentemente, na saúde da população, atentando para a correta forma de descarte de cada rejeito do processo radiográfico.

DESCRITORES: Radiologia, Meio ambiente, Resíduos odontológicos, Meio ambiente e saúde pública

\section{ABSTRACT}

The irregular disposal of health waste, especially dental care, is becoming a great concern. The waste tailings from the radiographic process is not different, since, apart from contaminated waste, there are chemical waste, heavy metals and plastics. Namely: casing radiographic film, processing solutions, blade lead, radiographic films - all they with large capacity to cause impact on the environment if disposed incorrectly. For this reason it is essential to educate dentists in the harmful impact on the environment and consequently on the health of people, paying attention to the correct way to dispose of each reject of the radiographic process.

DESCRIPTORS: Radiology, Environment, Dental waste, Environment and public health

* Graduando $2^{\circ}$ ano do curso de Odontologia da Universidade Estadual de Londrina (UEL)

** Professora Adjunta - Departamento de Medicina Oral e Odontologia Infantil / UEL

*** Residente do curso de Radiologia Odontológica e Imaginologia / UEL 
MOLINA $A B$

BUENO CS

AIDA CA

CASTANHEIRA GM

HADA RA

ISHIKIRIYAMA YT

ONOE

BRASSAROTO GC

A RADIOLOGIA ODONTOLÓGICA E - Meio AMBiENTE

REV, ODONTOL,

UNIV, CID, SÃO

PAULO

$2014 ; 26(1): 61-$

70 , JAN-ABR

\section{N T RO DUÇÃO}

Atualmente, um assunto muito abordado é a preservação do meio ambiente e, com ele, a preocupação cada vez maior em separar e reciclar o lixo. No dia a dia, as pessoas estão se habituando a separar lixo orgânico do reciclável e, ainda, vidro, papel, plástico e metal.

$\mathrm{Na}$ Odontologia não é diferente. O meio ambiente é uma preocupação constante para os dentistas e governantes, uma vez que seus resíduos e o descarte incorreto podem não só ser prejudiciais ao meio ambiente, como também à saúde da população. Esses resíduos, classificados como lixo hospitalar ou resíduos de serviços de saúde, podem ser altamente tóxicos e infecciosos.

Dentro da Odontologia, a Radiologia Odontológica e os materiais necessários para formar a imagem radiográfica são grandes fontes de resíduos poluidores. Assim como o lixo comum, em alguns casos, os resíduos radiológicos podem ser reciclados - como exames radiográficos descartados, dos quais pode-se recuperar a prata e a base de poliéster -, reutilizados - como as caixas de filmes extrabucais, as quais são usadas para armazenar radiografias -, ou devem ser tratados antes de serem descartados no meio ambiente.

Cientes de que, dentre os objetivos do curso de Odontologia da Universidade Estadual de Londrina (UEL) e de muitos outros cursos de Odontologia do Brasil, o profissional deverá reconhecer o impacto da prática odontológica sobre o meio ambiente e colaborar para que esta seja menos danosa possível, e considerando a Radiologia essencial ao processo diagnóstico em Odontologia e presente na maioria das especialidades para elaboração do plano de tratamento, é o objetivo deste trabalho apontar a importância da preservação do meio ambiente, dos resíduos odontológicos - mais especificamente radiológicos -, seus efeitos e sua correta forma de descarte.

\section{REVISÃO DE LITERATURA}

O planeta vem sofrendo cada vez mais danos ambientais pelos atos inconscientes dos seres humanos que o degradam e po- luem. Rios, lagos, zonas costeiras e baías são constantemente agredidos por despejos de volumes crescentes de depósitos de resíduos e dejetos industriais e orgânicos. O lançamento de esgoto não tratado aumentou dramaticamente nas últimas décadas, com impactos severos sobre a natureza ${ }^{1}$.

Trata-se de um desafio a ser superado pelo poder público, pois são diversas as atividades humanas geradoras do grande volume de resíduos, principalmente nas grandes cidades, tendo como consequência efeitos prejudiciais ao meio ambiente.

Contudo, segundo Morais² (2011), o problema não é a geração de resíduos, mas o destino final ligado à possibilidade de tratamento deles. Fenômeno agravado pela falta de recursos financeiros e tecnológicos para que haja o gerenciamento desses resíduos, situação apresentada, principalmente, nos países em desenvolvimento.

Dentre todos os resíduos sólidos urbanos gerados, aqueles provenientes dos serviços de saúde são os que mais chamam a atenção, pois representam elevado potencial de risco ao meio ambiente e à saúde, apesar de representarem uma pequena parcela ( 1 a $3 \%$ ) do total ${ }^{3}$.

De acordo com Silva e Hoppe ${ }^{4}$ (2005), são considerados resíduos de serviços de saúde (RSS) aqueles gerados por prestadores de assistência médica, farmacêutica, odontológica, laboratorial e instituições de ensino e pesquisa médica, tanto relacionadas à população humana quanta à veterinária.

Os resíduos de serviços de saúde, segundo Brasil (2006):

[...] são reservatórios de microorganismos de alta periculosidade. Inúmeros são os danos decorrentes do seu mau gerenciamento, como: a contaminação do meio ambiente, a ocorrência de acidente de trabalho que envolve profissionais de saúde, da limpeza pública e até catadores, o que pode ocasionar uma propagação de doenças por meio de vetores, contato direto ou indireto. 
Atualmente, é comum o gerenciamento inadequado dos RSS. Vários tipos desses resíduos contaminantes são descartados em aterros ou lixões (criados para acomodação de lixo doméstico) pelo fato de estarem co-dispostos com outros materiais (Carone, 2000 apud Pedrosa et al., 2007) pelo fato de estarem co-dispostos com outros materiais ${ }^{5}$. Além dos lixões a céu aberto, os RSS também são descartados em locais como matas e nascentes, causando a contaminação do solo, da água e do ar.

Uma pesquisa realizada pelo IBGE, a Pesquisa Nacional de Saneamento Básico (Política Nacional de Sanemento Básico 2000), demonstrou que dos 5.507 municípios brasileiros abordados, a maioria não possuía um sistema adequado para realização da coleta, do tratamento e da disposição final dos resíduos resultantes dos serviços de saúde. Apenas 63\% apresentaram a realização da coleta desses resíduos. Em consideração ao destino final, constatou-se que cerca de $56 \%$ dos municípios dispunham os RSS no solo, 30\% desse total equivalendo aos lixões. Os demais depositavam em aterros especiais, aterros controlados e sanitários. No que tange às formas de tratamento aderidas pelos municípios, verificou-se o predomínio da queima a céu aberto, representando cerca de $20 \%$ contra $11 \%$ do método de incineração. Apenas $0,8 \%$ dos municípios realizavam a desinfecção dos RSS através das tecnologias de microondas e autoclave. Do total dos municípios pesquisados, constou-se que cerca de $22 \%$ não realizam nenhum tipo de tratamento dos seus RSS 3 .

$\mathrm{Na}$ área da Odontologia, todo procedimento produz resíduos que podem ser prejudiciais à saúde de pacientes e profissionais submetidos a um contato direto ou indireto. Dentre os resíduos gerados, os mais importantes são: materiais perfurocortantes e com contaminação de saliva ou sangue; sobras de amálgama; lâminas de chumbo provenientes das películas radiográficas e soluções processadoras de filme radiográfico; soluções desinfetantes; medicamentos que não devem ser consumidos ${ }^{6}$.

Os resíduos provenientes dos serviços odontológicos, de acordo com Silva (2006 apud Morais $^{2}$, 2011), abrangem aspectos intra e extra-estabelecimentos. Os resíduos são gerados, segregados e acondicionados diretamente pelos profissionais, por isso há o envolvimento das dimensões intra-estabelecimentos. A esfera extra-estabelecimentos engloba a forma de manipulação dos resíduos ligada ao grau de periculosidade que representam à saúde coletiva e ambiental.

\section{RESÍdUOS GERADOS NO SERVIÇO DE RADIOLOGIA ODONTOLÓGICA}

Para a obtenção da imagem radiográfica convencional, é necessária a utilização do filme radiográfico, que é composto, principalmente, por emulsão e base. A gelatina que forma a emulsão é impregnada por cristais de sais halogenados (brometo ou iodeto) de prata. A base é um suporte de material plástico sobre o qual a emulsão é colocada. Um papel preto, opaco à luz, envolve o filme radiográfico intrabucal, cuja embalagem apresenta ainda uma lâmina de chumbo, com a finalidade de protegê-lo contra a radiação secundária, e invólucro de plástico ${ }^{7}$.

São necessárias, também, soluções de processamento. A solução reveladora reduz todos os íons de prata presentes nos cristais halogenados de prata expostos, em grãos de prata metálica, e produz uma imagem latente. $\mathrm{E}$ as soluções fixadoras têm como principal função dissolver e remover da emulsão os cristais halogenados de prata não revelados ${ }^{7}$.

Os materiais radiológicos utilizados, quando não descartados corretamente, produzem risco ambiental e à saúde da população. Os resíduos desses materiais, inclusive aqueles deixados nas soluções químicas utilizadas durante o processamento radiográfico, são considerados tóxicos ao ser humano ${ }^{8}$. Por esse motivo, geradores desse tipo de resíduos devem atender à resolução adotada pela Agência Nacional de Vigilância Sanitária (ANVISA), a RDC - Resolução da Diretoria Colegiada - ANVISA no ${ }^{\circ}$ 306, que dispõe sobre o gerenciamento interno e externo dos RSS, incluindo os efluentes utilizados para o processamento de radiografias (Brasil, 2006), minimizando, assim, o impacto
MOLINA AB

BUENO CS

AIDA CA

CASTANHEIRA GM

HADA RA

ISHIKIRIYAMA YT

ONO E

BRASSAROTO GC

A RADIOLOGIA

ODONTOLÓGICA E

O MEIO AMBIENTE

\section{3}

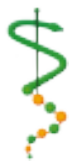

REV, ODONTOL.

UNIV, CID, SÃo

PAULO

2014; 26(1): 61

$70, J A N-A B R$ 
MOLINA $A B$

BUENO CS

AIDA CA

CASTANHEIRA GM

HADA RA

ISHIKIRIYAMA YT

ONOE

BRASSAROTO GC

A RADIOLOGIA ODONTOLÓGICA E - Meio AMBiENTE

\section{4}

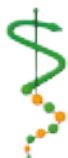

REV. ODONTOL,

UNIV. CID. SÃO

PAULO

$2014 ; 26(1): 61$ -

70 , JAN-ABR ambiental provocado por eles 9 .

A seguir, abordamos cada componente utilizado para obtenção da imagem radiográfica, assim como seu descarte, seus efeitos no meio ambiente e na saúde da população.

Invólucros de Filmes Radiográficos

Em Radiologia odontológica, pacientes e profissionais estão expostos à contaminação por meio de microrganismos potencialmente infecciosos, que podem ser transmitidos principalmente pela saliva e sangue. Essa contaminação pode ocorrer durante a realização de radiografias intrabucais pela presença de microrganismos nos filmes radiográficos. O invólucro do filme é um veículo de potencial contaminação cruzada na radiologia odontológica. O momento de maior contaminação ocorre quando o filme intrabucal é retirado da cavidade oral do paciente pelo operador e é colocado sobre outras superfícies. Os fluidos bucais são capazes de contaminar também os líquidos utilizados no processamento radiográfico se, durante a abertura dos invólucros, houver a contaminação do filme. A melhor alternativa para minimizar a contaminação é a utilização de embalagens plásticas de polipropileno seladas em seladoras, pois apresentam um resultado parcial satisfatório, são de fácil manuseio e baixo custo. Outra opção é a imersão dos filmes periapicais em solução de álcool a 70\% ou em hipoclorito de sódio a 5\% por ao menos 30 segundos; esta se mostra com eficácia de $100 \%{ }^{10}$.

O polímero utilizado para a produção do invólucro é chamado de polietileno de baixa densidade (LDPE) porque ele flutua em uma mistura de álcool e água. Pelo fato de o LDP ser um derivado do petróleo, ele não se deteriora no meio ambiente, mas pode ser reciclado ${ }^{11}$.

Os invólucros dos filmes radiográficos são considerados resíduos com risco biológico (Grupo A) e, como tais, devem seguir o Plano de Gerenciamento dos Resíduos de Serviços de Saúde (PGRSS) (Portal Educação ${ }^{12}$, 2008), o qual estipula o devido tratamento com relação a esses resíduos.

\section{Soluções Processadoras}

Embora a radiografia digital venha sen- do mais amplamente utilizada, o uso de filmes e o processamento radiográfico manual ainda são rotina na prática odontológica. Entretanto, no processo de revelação radiográfica, efluentes são produzidos e estes contêm metais pesados em sua composição, os quais estão acima do permitido para o descarte. Quando eliminados de forma imprudente, poderão causar riscos ao meio ambiente e à saúde de animais e humanos por meio da contaminação do solo e das águas. Efeitos danosos acontecem no meio ambiente devido à bioacumulação das soluções, isto é, animais e plantas, que são contaminados, passam a ter maior concentração de substâncias nocivas em seu organismo, tornando-se, assim, menos saudáveis ou até mesmo perigosos quando consumidos com frequência ${ }^{8}$.

A Diretoria Colegiada da Agência Nacional de Vigilância Sanitária - ANVISA aprovou o Regulamento Técnico para o Gerenciamento de Resíduos de Serviços da Saúde. No que diz respeito a resíduos gerados na Radiologia, o Regulamento apresenta os seguintes critérios: Para atingirem um $\mathrm{pH}$ tolerável, ou seja, em torno de 7 e 9, os reveladores utilizados em Radiologia passariam por um processo de neutralização e, somente após esse procedimento, poderiam ser lançados na rede coletora de esgoto ou em corpo receptor, sempre respeitando as diretrizes estabelecidas por órgãos ambientais, gestores de recursos hídricos e de saneamento competentes. Do contrário, deve-se reunir a solução em frascos identificados e enviá- los a uma empresa de tratamento biológico de resíduos líquidos, devidamente licenciada por um órgão ambiental. As soluções fixadoras exauridas ou usadas, por terem a função de fixar a imagem após a revelação, contêm toda a prata não exposta no processo; portanto, elas devem passar por um sistema de recuperação da pra$\mathrm{ta}^{13}$. Esse metal é um elemento com alto valor de mercado e com risco de escassez (Bortoletto, 2005 apud Oliveira, 2006). A prata é relevante, pois, além de ser metal pesado, apresenta um potencial de contaminação ao meio ambiente ${ }^{13}$. Ademais, os íons de prata livres atuam como enzimas inibidoras, interferindo nos processos me- 
tabólicos dos organismos (Thunthy, 1990 apud Oliveira, 2006). Alguns dos efeitos do metal sobre o homem são: distúrbios digestivos, impregnação da boca pelo metal e argiria, uma intoxicação crônica que provoca uma coloração azulada da pele ${ }^{13}$. A solução fixadora causa irritação nos olhos e a reveladora, além dos olhos, prejudica a pele ${ }^{8}$.

No processo de revelação radiográfica, a água resultante da lavagem também constitui um componente do efluente que contém todos os compostos do revelador, do fixador e de seus produtos de reação, incluindo a prata, o que também a torna carente de tratamento antes de ser lançada na rede de esgotos ${ }^{8}$.

Os resíduos formados pelo processo de obtenção da radiografia, de acordo com a RDC 306/2004, se destinados à reciclagem, deverão ser dispostos em recipientes individualizados, e deve-se respeitar as exigências de compatibilidade química entre o resíduo e o material da embalagem, para que não ocorra reação química entre eles (Brasil, 2004 apud Carvalho et al., 2006). Deverão ser armazenadas em frascos de até $2 \mathrm{~L}$ todas as soluções processadoras (revelador e fixador) concentradas e as que não foram utilizadas ${ }^{13}$.

\section{Lâminas de Chumbo}

O chumbo (pb), na Odontologia, é usado principalmente nos filmes radiográficos, como película de proteção contra radiações. A película é descartada durante o processo de revelação, descarte este muitas vezes incorreto e inconsequente, sendo a película simplesmente jogada em aterros ou lixões. Assim, o chumbo penetra e se acomoda tanto no solo como em lençóis freáticos ${ }^{14}$.

A intoxicação por via oral ainda é a mais comum para o chumbo. Cerca de $80 \%$ do pb ingerido são oriundos de alimentos, sujeiras e poeiras contendo o metal. Aproximadamente $60 \%$ do chumbo são absorvidos pelo corpo, provocando inúmeras altrações bioquímicas. O pb afeta o sistema neuromuscular, neurológico, gastrointestinal, hematológico e renal. As pessoas acometidas pela intoxicação crônica de chumbo podem apresentar os seguintes sintomas: fraqueza, irritabilidade, falta de coordenação, náusea, dor abdo- minal, anemia etc., sendo as crianças as mais suscetíveis aos efeitos do chumbo ${ }^{15}$.

A lâmina de chumbo é erroneamente reutilizada no registro de mordidas, pois, uma vez em contato com secreções bucais, é considerada como resíduo contaminado. O tratamento dos resíduos com metais pesados em sua composição, como as lâminas de chumbo, deverá ser processado em instalações licenciadas para esse fim, seguindo as orientações do órgão local de meio ambiente, podendo também ser encaminhados a um Aterro Sanitário Industrial para Resíduos perigosos - Classe ${ }^{13}$.

\section{Películas de Filmes Radiográficos}

Além dos efluentes do processamento radiográfico e de todos os outros resíduos sólidos, a prática radiológica também gera, como resíduo, o próprio filme radiográfico. Este é considerado um contaminante potencial, pois, de acordo com Piva; Wiebeck (2004 apud Kawaguti ${ }^{16}$ et al., 2011), ele é constituído por uma base de poliéster PET (Poli-Tereftalato de Etileno) - um tipo de plástico muito utilizado para fabricação de garrafas de refrigerantes. Devido à prata contida nos filmes radiográficos, eles são considerados resíduos tóxicos, que podem agir nos organismos vivos e danificar suas estruturas biomoleculares, como os aspectos carcinogênicos, mutagênicos, entre outros (Valle, 2004 apud Kawaguti ${ }^{16}$ ). Além da prata, outras substâncias tóxicas, prejudiciais ao meio ambiente, quando do descarte incorreto, estão contidas nas radiografias, tais como o metanol, amônia e cromo. Portanto, o filme radiográfico deve ser reciclado, havendo obtenção da prata e plásticos que, ao serem comercializados, geram lucro e evitam danos ao meio ambiente e à saúde da população ${ }^{16}$. Porém, habitualmente, apenas a prata recuperada é reaproveitada por causa do seu valor comercial significativo. E a película radiográfica acaba inadequadamente descartada no meio ambiente ${ }^{17}$.

De acordo com Thunthy (1990 apud Oliveira, 2006), os filmes radiográficos dos consultórios odontológicos que vão para o lixo comum, na maioria das vezes, são os rejeitos, isto é, são originados de tomadas radiográficas insatisfatórias, são
MOLINA AB

BUENO CS

AIDA CA

CASTANHEIRA GM

HADA RA

ISHIKIRIYAMA YT

ONO E

BRASSAROTO GC

A RADIOLOGIA

ODONTOLÓGICA E

o MEIO AMBIENTE

65

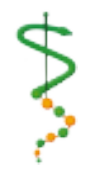

REV, ODONTOL.

UNIV, CID, SÃo

PAULO

2014; 26(1): 61 -

70 , JAN-ABR 
MOLINA AB

BUENO CS

AIDA CA

CASTANHEIRA GM

HADA RA

ISHIKIRIYAMA YT

ONO E

BRASSAROTO GC

A RADIOLOGIA ODONTOLÓGICA E - Meio AMBiENTE

REV, ODONTOL, UNIV, CID, SÃO

PAULO

$2014 ; 26(1): 61-$

70 , JAN-ABR considerados velhos ou não têm valor útil.

Quanto aos filmes radiográficos que as pessoas levam para casa, geralmente acabam parando em lixões e aterros, podendo causar a contaminação do solo e lençóis freáticos. Isso demonstra a necessidade da conscientização da população (Calderari, 2008 apud Kawaguti ${ }^{16}$ ). É necessário que haja, também, incentivos à criação de postos de coleta em locais próximos, como unidades de saúde, escolas e comércios $^{16}$.

Recuperação da prata a partir de radiografias

Vivemos a atual necessidade de suprir a demanda por matérias-primas básicas. Como um dos conceitos da Odontologia sustentável, é imprescindível auxiliar na reciclagem da prata contida nas radiografias $^{18}$.

A taxa de prata impregnada em negativos de filmes comuns de fotografia é de aproximadamente $0,5 \mathrm{~g} / \mathrm{m}^{2}$, enquanto nos filmes radiográficos, a quantidade encontrada chega a ser até dez vezes maior, o que mostra maior vantagem econômica para os chamados recicladores de filmes. Algumas técnicas para recuperação de prata a partir de filmes vêm sendo estudadas e desenvolvidas e constata-se que muitas dessas técnicas, apesar da eficiência na recuperação do metal, produzem resíduos considerados extremamente tóxicos que são descartados no meio ambiente e o consumo de energia elétrica é elevado, porém há métodos mais baratos e sem geração de resíduos químicos ${ }^{19}$.

\section{Formas de Descarte}

Todo gerador deve elaborar um Plano de Gerenciamento dos Resíduos de Serviços de Saúde, baseado nas características dos resíduos produzidos e na classificação constante da RDC, ANVISA n ${ }^{\circ} 306$, onde são estabelecidas as diretrizes de manejo dos RSS2.

Brasil (2006) dispõe que, de acordo com a RDC ANVISA no 306/04 e a Resolução CONAMA no 358/05, os resíduos dos serviços de saúde "são classificados em função de suas características e consequentes riscos que podem acarretar ao meio ambiente e à saúde". Eles são divididos em cinco grupos, sendo: Grupo A - resíduos com risco biológico que apre- sentam risco de infecção devido às suas características de maior virulência ou concentração (exemplo: materiais contendo sangue); Grupo B - resíduos com risco químico (exemplos: resíduos que contenham metais pesados como mercúrio e chumbo, efluentes de processadores de imagem, reveladores e fixadores); Grupo C - rejeitos radioativos (exemplo: rejeitos contendo materiais emissores de radiação ionizante, usados em procedimentos de diagnóstico e terapia); Grupo D - resíduos semelhantes aos domiciliares (exemplos: resíduos advindos das áreas administrativas); Grupo E - resíduos perfurocortantes (exemplos: agulhas, lâminas de bisturi, brocas, limas endodônticas).

Brasil (2006) dispõe que o gerenciamento dos resíduos de serviços de saúde, segundo a RDC ANVISA no 306/04:

[...] consiste em um conjunto de procedimentos planejados e implementados, a partir de bases científicas e técnicas, normativas e legais. Tem o objetivo de minimizar a geração de resíduos e proporcionar aos mesmos um manejo seguro, de forma eficiente, visando a proteção dos trabalhadores, a preservação da saúde, dos recursos naturais e do meio ambiente.

A primeira etapa do gerenciamento dos RSS consiste na segregação. Os resíduos são separados no próprio local assim que são gerados, considerando-se suas características biológicas, químicas, físicas e o seu estado físico, além dos riscos envolvidos. A fim de proporcionar o correto manejo dos RSS, a identificação dos resíduos contidos nos sacos e recipientes de coleta interna e externa deve ser facilitada pelo uso de símbolos, cores e frases para cada grupo de resíduos ${ }^{3}$.

O acondicionamento dos RSS deve ser realizado, de acordo com suas características, em sacos simbolizados, resistentes à ruptura e ao vazamento, impermeáveis; o limite de peso de cada saco deve ser respeitado e proibido o seu esvaziamento ou reapproveitamento. Para o acondicionamento de resíduos líquidos, os recipientes devem, além de ser compostos 
de material compatível com a substância a ser armazenada, ser rígidos, resistentes e estanques, providos de tampa rosqueada e vedante. Os resíduos devem ficar em recipientes coletores adequados e não diretamente sobre o piso. O ambiente deve ser fechado, provido de aberturas teladas para ventilação e com dispositivo impedindo a luz solar direta. Mas caso o local do armazenamento externo seja próximo ao de geração, essa etapa pode ser pulada. O armazenamento externo dos resíduos deve ser, também, em ambiente exclusivo e em recipientes coletores adequados. Esse ambiente deve ser dimensionado em conformidade com o volume de resíduos gerados, sendo compatível a capacidade de armazenamento com a periodicidade da coleta. Deve, também, apresentar divisões, havendo, no mínimo, uma parte destinada ao armazenamento dos resíduos do Grupo A junto com os do Grupo E e uma parte própria para resíduos do Grupo D. O abrigo deve, ainda, proporcionar fácil acesso para os veículos coletores, além de ser seguro, evitando o acesso ao local por animais ou pessoas não autorizadas ${ }^{3}$.

Feito o armazenamento externo, os próximos estágios da gestão dos resíduos são: a coleta, o tratamento e a disposição final. Os estabelecimentos prestadores de serviços de saúde podem contratar empresas terceirizadas para auxiliá-los nessas etapas finais. Mas a responsabilidade pelos resíduos, além de se estender às empresas, ainda permanece com os geradores. Portanto, na contratação, deve-se assegurar o cumprimento das legislações vigentes para realização dos serviços. $\mathrm{Na}$ coleta externa, com o uso de veículos, os resíduos, ao serem removidos do abrigo de resíduos, são encaminhados para a unidade de tratamento ou disposição final. Tal procedimento deve assegurar a preservação das condições de acondicionamento, garantindo a integridade dos trabalhadores, da população e do meio ambiente, e agindo conforme as regulamentações do órgão de limpeza urbana. Alguns RSS, antes da disposição final, necessitam passar pela etapa do tratamento, que é um procedimento que, ao alterar as características dos riscos inerentes aos resíduos, elimina ou reduz o risco de contamina- ção, de acidentes ou de danos ao meio ambiente. Pode ser realizado no próprio estabelecimento gerador ou em outro local (empresa terceirizada), sendo que os sistemas utilizados devem ser objeto de licenciamento ambiental. O tratamento pode ser executado de várias maneiras: desinfecção térmica realizada pela autoclavagem, microondas ou incineração, ou desinfecção química. A última etapa do gerenciamento dos RSS consiste na disposição final dos resíduos, considerada a disposição definitiva no solo ou em locais previamente desenvolvidos para recebê-los, sendo obrigatório eles apresentarem licenciamento ambiental, onde critérios técnicos de construção e operação são respeitados. Atualmente, as formas de disposição final utilizadas são: aterros sanitários, aterros de resíduos perigosos Classe I (para resíduos industriais), aterros controlados, lixões ou vazadouros e valas ${ }^{3}$.

O correto gerenciamento de todos os RSS é de responsabilidade direta dos estabelecimentos de serviços de saúde, pois eles são os geradores. Contudo, tal responsabilidade se estende ao poder público e às empresas de coleta, tratamento e disposição final. Desde que a ANVISA publicou, em 7 de dezembro de 2004, a RDC 306/04, esta deve ser cumprida em um prazo máximo de 180 dias pelos estabelecimentos prestadores de serviços de saúde e os novos prestadores e aqueles que pretendam retomar suas atividades só poderão entrar em funcionamento desde que estejam integralmente em cumprimento com as exigências da Resolução ${ }^{3}$.

O não cumprimento da Resolução da ANVISA sucede pela falta de conhecimento sobre o assunto, além da falta de infraestrutura para realizar adequadamente o gerenciamento dos resíduos de serviços de saúde (Bohner et al., 2012). Porém, aqueles que descumprirem as normas constantes na Resolução, estarão sujeitos a punições de acordo com a Lei $n^{\circ} 6.437 / 1977$, recebendo desde notificações a multas que variam de $\mathrm{R} \$ 2 \mathrm{mil}$ a R\$ 1,5 milhão (Brasil, 1977) ${ }^{20}$. E, além dessa lei, há duas outras, a Lei dos Crimes Ambientais (Lei no 9.605/98) e a Lei de Política Nacional do Meio Ambiente (Lei $n^{\circ} 6.938 / 81$, Artigo $3^{\circ}$ ), que respon-
MOLINA AB

BUENO CS

AIDA CA

CASTANHEIRA GM

HADA RA

ISHIKIRIYAMA YT

ONO E

BRASSAROTO GC

A RADIOLOGIA

ODONTOLÓGICA E

o MEIO AMBiENTE

\section{7}

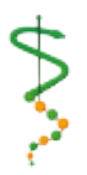

REV, ODONTOL.

UNIV. CID. SÃO

PAULO

2014; $26(1)$ : 61 -

70 , JAN-ABR 
MOLINA $A B$

BUENO CS

AIDA CA

CASTANHEIRA GM

HADA RA

ISHIKIRIYAMA YT

ONO E

BRASSAROTO GC

A RADIOLOGIA ODONTOLÓGICA E - Meio AMBiENTE

REV, ODONTOL. UNIV. CID, SÃO

PAULO

$2014 ; 26(1): 61$ -

70 , JAN-ABR
I SSN 1983-5183

sabilizam civil, administrativa e criminalmente as pessoas físicas e jurídicas, que sejam autoras e coautoras de atividades ou condutas lesivas ao meio ambiente. Portanto, é obrigação das fontes geradoras de RSS adotarem tecnologias mais limpas, empregarem métodos de recuperação e reutilização sempre que for possível, além de incentivarem a reciclagem e destinarem adequadamente os resíduos, compreendendo etapas de transporte, tratamento e disposição final (Brasil, 2006).

A gestão, regulamentação e fiscalização são deveres dos órgãos públicos, dentro de suas competências. Com a ajuda dos Órgãos de Meio Ambiente, Limpeza Urbana, e Comissão Nacional de Energia Nuclear (CNEN), cabe à Vigilância Sanitária dos Estados, Municípios e Distrito Federal, a divulgação, orientação e fiscalização da execução desta Resolução, RDC 306/04

\section{I SCUSSÃO}

Conforme Brasil (2006), as empresas prestadoras de serviços radiológicos, assim como todos os estabelecimentos prestadores de serviços de saúde, devem gerenciar todo seu resíduo gerado através da implantação do Plano de Gerenciamento dos Resíduos de Serviços de Saúde. Esse documento aponta e descreve as ações referentes às etapas de: segregação, acondicionamento, coleta, armazenamento, transporte, tratamento e disposição final.

Os resíduos gerados pela prática radiológica consistem em: efluentes - soluções reveladora e fixadora mais a água utilizada para a lavagem; filmes radiográficos; lâminas de chumbo e invólucros de filme radiográfico. Considerando-se a classificação dos resíduos provenientes de serviços de saúde, feita pela RDC ANVISA $n^{\circ} 306 / 04$ e pela Resolução CONAMA no 358/05, apenas o invólucro de filme radiográfico encaixa-se no grupo dos resíduos com risco biológico (Grupo A). Conforme o disposto pela RDC ANVISA no 306/04, os invólucros de filmes radiográficos podem ser dispostos em local devidamente licenciado para disposição final de Resíduos de Serviços de Saúde (RSS) sem a necessidade de tratamento prévio.
Todos os outros resíduos - efluentes, filmes radiográficos e lâminas de chumbo - são classificados como resíduos com risco químico. De acordo com Brasil (2006), resíduos químicos que representam risco ao meio ambiente ou à saúde podem ser reutilizados, recuperados ou reciclados, senão tratados ou dispostos em locais específicos. Previamente ao lançamento da solução reveladora na rede coletora de esgoto ou em corpo receptor, esta pode ser neutralizada ( $\mathrm{pH}$ entre 7 e 9). As soluções fixadoras podem ser submetidas ao processo de recuperação da prata. Da mesma forma, a prata dos filmes radiográficos também pode ser recuperada e o poliéster reaproveitado para criar embalagens. Esse processo de reciclagem, além de colaborar com a preservação do meio ambiente, é uma maneira de gerar renda. A lâmina de chumbo, de acordo com Carvalho ${ }^{13}$ et al. (2013), se não for tratada, deverá ser encaminhada a um Aterro Sanitário Industrial para Resíduos Perigosos - Classe I.

Embora existam diretrizes técnicas e legais, constantes na RDC ANVISA $n^{\circ}$ 306/04, sobre como gerenciar RSS no Brasil, assim como legislações que são claras em relação à consequência do não cumprimento dessas diretrizes e consequente prejuízo ao meio ambiente e à população, os autores Pedrosa et al. (2007), Thunthy (1990 apud Oliveira ${ }^{9}$, 2006) e Fernandes (2005 apud Oliveira ${ }^{9}$, 2006) mostram que muitas clínicas prestadoras de serviços radiológicos ainda descartam incorretamente seus efluentes e resíduos.

De acordo com Bohner et al. ${ }^{8}$ 2012, o descumprimento desta Resolução é devido à falta de infraestrutura para realizar adequadamente o gerenciamento dos resíduos, além da carência de conhecimento sobre o assunto. Isso evidencia a necessidade da conscientização de acadêmicos e profissionais cirurgiões-dentistas e da orientação sobre os locais e formas adequados para o descarte dos resíduos radiológicos contaminados e também sobre o impacto causado pelo não cumprimento das normas.

De acordo com Brasil ${ }^{20}$ (2006), quanto às etapas finais do gerenciamento dos RSS - coleta, tratamento e disposição final -, os estabelecimentos prestadores de servi- 
ços de saúde podem contratar empresas terceirizadas para realizá-las; assegurando-se de que tais empresas estejam cumprindo as legislações vigentes.

Em um apanhado geral, o grande problema é: Como formular um Plano de Gerenciamento dos Resíduos de Serviços de Saúde, se as mais básicas regras da Vigilância Sanitária são negligenciadas? Como lutar e cobrar se estamos errados? Somente após mudarmos essas ideias estagnadas, poderemos caminhar e pôr em prática a metodologia "Odontologia Sustentável".

A principal solução advém do fato de melhor escolher representantes da população, adverti-los sobre os problemas estruturais, e lutar para solucioná-los. Assim sendo, será possível cobrar as medidas básicas. A solução virá da maior atuação da classe odontóloga na política e organização pública.

\section{CONCLUSÃO}

Uma das razões pela grande preocupação com o meio ambiente é devida ao fato de que os resíduos que produzimos, quando descartados incorretamente, são prejudiciais ao ambiente e à saúde. Inclusive os resíduos de serviços de saúde, que são altamente tóxicos e infecciosos, quando não tratados ou destinados para locais adequados.

Mas, apesar dessa grande preocupação mundial com o meio ambiente, nota-se que os próprios causadores de danos à natureza e à saúde humana não estão preocupados com a sua preservação. Portanto, há a necessidade de uma fiscalização da Vigilância Sanitária mais rigorosa, notificando e multando estabelecimentos prestadores de serviços de saúde que não estejam em cumprimento com a RDC ANVISA n ${ }^{\circ} 306 / 04$. Dessa maneira, os infratores serão obrigados a atuar de tal forma que o impacto ambiental causado pelos resíduos gerados será menor.

Além do mais, é primordial que acadêmicos e profissionais cirurgiões-dentistas sejam conscientizados quanto ao impacto ambiental causado pelos resíduos odontológicos, e orientados em relação à forma de descarte destes.

\section{REFERÊNCIAS}

1. Jornal Pequeno. Resíduos são jogados direto na rede de esgotos por dentistas, segundo estudo. 2011 [Acesso 19 setembro 2013]; Disponível em: http://jornalpequeno.com.br/edicao/2011/01/23/residuos-quimicos-sao-jogados-direto-na-rede-de-esgoto-por-odontologos.

2. Morais L. Avaliação do plano de gerenciamento de resíduos de serviços de saúde da área odontológica [Dissertação]. Anápolis: Centro Universitário de Anápolis; 2011.

3. BRASIL MdS. Manual de gerenciamento de resíduos de serviços de saúde. Brasília: Ministério da Saúde; 2006.

4. Silva CE, Hoppe AE. Diagnóstico dos resíduos de serviços de saúde no interior do Rio Grande do Sul. Engenharia Sanitaria e Ambiental 2005 abr/ jun;10(2):146-51.
5. Pedrosa HLO, Figueiredo RLQ, Albuquerque TTPA, Costa EB. Avaliação dos cirurgiões-dentistas sobre o gerenciamento dos resíduos odontológicos produzidos na prática diária. Arquivos em Odontologia 2007 out/dez;43(4):

6. Gusmão M. A importância do plano de gerenciamento de resíduos odontológicos nas organizações militares de saúde do exército brasileiro [Trabalho de Conclusão de Curso]. Rio de Janeiro: Escola de Saúde de Exército; 2009.

7. White SC, MJ. P. Radiologia oral: fundamentos e interpretação. 5 ed. Rio de Janeiro: Elsevier; 2007.
MOLINA AB

BUENO CS

AIDA CA

CASTANHEIRA GM

HADA RA

ISHIKIRIYAMA YT

ONO E

BRASSAROTO GC

A RADIOLOGIA

ODONTOLÓGICA E

o Meio ambiente

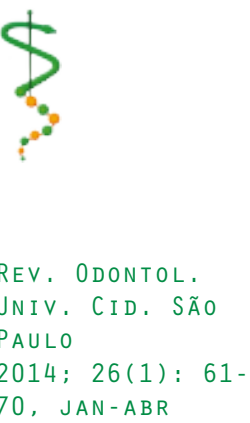


MOLINA $A B$

BUENO CS

AIDA CA

CASTANHEIRA GM

HADA RA

ISHIKIRIYAMA YT

ONOE

BRASSAROTO GC

A RADIOLOGIA ODONTOLÓGICA E - Meio AMBiENTE
8. Bohner L, Bohner T, Mafaldo I, Peres P, Rosa M. Difusão de material informativo sobre o descarte de resíduos radiológicos entre acadêmicos de odontologia e cirurgiões-dentistas da Região Sul do Brasil. Revista Eletrônica do Curso de Especialização em Educação Ambiental da UFSM [serial on the Internet]. 2011 [Acesso 30 maio 2012.]; 3(2): Disponível em: http://cascavel. ufsm.br/revistas/ojs-2.2.2/index.php/ remoa/article/viewFile/3317/1840.

9. Oliveira P. Avaliação dos níveis de poluição ambiental dos serviços com radiologia odontológica na cidade de Itabuna [Dissertação]. Bahia: Universidade Estadual de Santa Cruz; 2006.

10. Salvador J, Vidotti B, Capelozza A. Biossegurança em técnicas radiográficas intrabucais: uso de barreiras de superfície em filmes periapicais. Revista ABRO 2006 jan/jun.;7(1):

11. Craig F. Como funciona o plástico. 2007 [Acesso 14 julho 2012]; Disponível em: http://ciencia.hsw.uol.com. br/plastico.htm.

12. Portal Educação. Plano de gerenciamento de resíduos de serviços da saúde. 2008 [Acesso 9 ago. 2012]; Disponível em: http://www.portaleducacao. com.br/odontologia/artigos/3068/plano-de-gerenciamento-de-residuos-de-servicos-de-saude.

13. Carvalho PL, Antoniazzi MCC, Medeiros JMF, Zöllner NA. Situações dos resíduos gerados em radiologia odontológica. Revista Biociências 2006 jul/ dez; 12(3-7):

14. Freitas A, Rosa J, Souza I. Radiologia odontológica. 5 ed. São Paulo: Artes Médicas; 2000.
15. Schifer T, Bogusz Junior S, Montano M. Aspectos toxicológicos do chumbo. Infarma 2005 17(5-6):

16. Kawaguti R, Baptista J, Pinheiro L. Análise da logística reversa das radiografias (chapa de raio-X). 2011 [Acesso 4 agosto 2012]; Disponível em: http://www.engema.org.br/upload/ pdf/2011/350-15.pdf.

17. Viriato A. Gerenciamento de resíduos e efluentes do Serviço de Diagnóstico por Imagem do Hospital Infantil Cândido Fontoura. s.d. [Acesso 4 agosto 2012]; Disponível em: http:// boletim.saludsindano.org/recursos\%20portugues/Gerenciamento $\% 20$ de $\% 20$ res $\%$ EDduos $\% 20$ e\%20 efluentes $\% 20$ do\%20Servi\%E7o\%20 de\%20Diagn\%F3stico\%20por\%20 Imagem\%20do\%20Hospital\%20Infantil\%20C\%E2nd.pdf.

18. Kimbrough D, Wong P, Biscoe J. A critical review of photographic and radiographic silver recycling. Journal of Solid Waste Technology and Management 1996 Nov.;23(4):

19. Recicloteca. Recuperação de prata a partir de radiografias. 2001 [Acesso 12 julho 2012]; Disponível em: http://www.recicloteca.org.br/Default. asp? Editoria $=3 \&$ SubEditoria $=11$.

20. BRASIL MS. Lei $n^{\circ}$ 6.437, de 20 de agosto de 1977. Configura infrações à legislação sanitária federal, estabelece as sanções respectivas, e dá outras providências. Brasília 2006; Disponível em: http://www.planalto.gov.br/ ccivil_03/LEIS/L6437.htm.

Recebido: 25/11/2013

Aceito: 02/02/2014

\footnotetext{
REV. ODONTOL. UNIV. CID. SÃO PAULO
} 2014; 26(1): 61 70 , JAN-ABR 